\title{
Influence of the amount of starch on the glycaemic index to rice in non-insulin-dependent diabetic subjects
}

\author{
BY O. RASMUSSEN AND S. GREGERSEN \\ Medical Department $M$ (Endocrinology and Diabetes), Aarhus Kommunehospital, \\ DK-8000 Aarhus C, Denmark \\ AND K. HERMANSEN \\ University Clinic of Endocrinology and Diabetes, Aarhus Amtssygchus, DK-8000 Aarhus C, \\ Denmark
}

(Received 20 December 1990 - Accepted 22 May 199I)

\begin{abstract}
To test whether the glycaemic index is altered by the amount of carbohydrate, meals containing 25 and $50 \mathrm{~g}$ carbohydrate as white rice and white bread were taken by seven non-insulin-dependent diabetic subjects. The glycaemic indices to parboiled white rice corresponding to 25 and 50 g carbohydrate were similar, being 55 (SE 10) and 60 (SE 8) respectively. The incremental areas of blood glucose (above basal) to parboiled white rice were significantly lower than to white bread after both an amount corresponding to $25 \mathrm{~g}$ carbohydrate (85 (SE 24) $\mathrm{mM} \times 180 \mathrm{~min}$ y. 181 (SE 55 ) $\mathrm{mM} \times 180 \mathrm{~min} ; P<0.01$ ) and to $50 \mathrm{~g}$ carbohydrate 226 (SE 29) $\mathrm{mM} \times 180 \mathrm{~min} v .423$ (SE 76) $\mathrm{mM} \times 180 \mathrm{~min} ; P<0.01$ ). Similar insulin response areas to $25 \mathrm{~g}$ carbohydrate given as parboiled white rice and white bread were found, whereas 50 g carbohydrate as white bread caused a significantly higher insulin response area than parboiled white rice $(P<0.05)$.

In conclusion, the glycaemic index of parboiled white rice is not affected by the amount of carbohydrate ingested, at least under the present study conditions.
\end{abstract}

Non-insulin-dependent diabetes mellitus: Glycaemic index : Rice

Post-prandial blood glucose and insulin responses to starch-rich foods vary considerably in both normal and diabetic subjects (Coulston et al. 1980; Crapo et al. 1980, 1981; Bantle et al. 1983; Jenkins et al. 1983, 1984; Hermansen et al. 1986, 1987; Hollenbeck et al. 1986; Rasmussen et al. 1989). Due to the large variation of glycaemic responses between individuals, the results are often difficult to interpret and to use in practical diet planning for diabetic subjects. Jenkins et al. (1981) introduced the concept of glycaemic indexing (GI), classifying the glycaemic response to $50 \mathrm{~g}$ carbohydrate $(\mathrm{CHO})$ of a particular food as a percentage of a standard meal of $50 \mathrm{~g} \mathrm{CHO}$ as glucose, in order to reduce inter-person variation (Wolever et al. 1989, 1990). Thus, the GI has been postulated to be an easy and practical implement for diabetic subjects to control post-prandial hyperglycaemia by selecting foods of low GI. Recent reports have found improved metabolic control and decreased plasma triacylglycerol levels after 2-3 weeks of switching from high to low GI foods in insulin-dependent diabetes mellitus (IDDM) and non-insulin-dependent diabetes mellitus (NIDDM), suggesting that the concept of the ' $\mathrm{GI}$ ' tested in acute conditions is valid on a chronic basis (Fontvieille et al. 1988; Jenkins et al. 1988). The question arises if the GI of a food depends on the amount of CHO. In other words if smaller amounts of food than $50 \mathrm{~g}$ CHO behave in a similar way with respect to the GI. This is a problem of daily life as mixed meals seldom contain more than $20-25 \mathrm{~g}$ CHO derived from a single 
Table 1. Clinical information for seven non-insulin-dependent diabetic patients

(Mean values with their standard errors)

\begin{tabular}{|c|c|c|c|c|c|c|c|c|}
\hline \multirow[b]{2}{*}{ Patient no. } & \multirow[b]{2}{*}{ Sex } & \multirow{2}{*}{$\begin{array}{c}\text { Age } \\
\text { (years) }\end{array}$} & \multirow{2}{*}{$\begin{array}{c}\text { Body mass } \\
\text { index } \\
\left(\mathrm{kg} / \mathrm{m}^{2}\right)\end{array}$} & \multirow{2}{*}{$\begin{array}{l}\text { Duration of } \\
\text { diabetes } \\
\text { (years) }\end{array}$} & \multicolumn{4}{|c|}{$\begin{array}{l}\text { Fasting blood glucose } \\
(\mathrm{mmol} / \mathrm{l}) \text { for meals: }\end{array}$} \\
\hline & & & & & A & B & $\mathrm{C}$ & D \\
\hline 1 & $F$ & 63 & 32.6 & 6 & 7.7 & $8 \cdot 8$ & 6.1 & 4.9 \\
\hline 2 & $\mathrm{~F}$ & 62 & $25 \cdot 4$ & 2 & 7.9 & 7.4 & 6.8 & 6.9 \\
\hline 3 & $\mathbf{M}$ & 58 & $27 \cdot 3$ & 8 & 6.6 & $7 \cdot 2$ & $9 \cdot 0$ & 8.4 \\
\hline 4 & $\mathrm{~F}$ & 62 & $25 \cdot 0$ & 2 & $9 \cdot 3$ & 7.5 & $6 \cdot 7$ & 7.3 \\
\hline 5 & $\mathrm{~F}$ & 63 & 35.9 & 14 & 7.5 & $8 \cdot 1$ & 8.0 & 8.1 \\
\hline 6 & M & 64 & $24 \cdot 5$ & 2 & $7 \cdot 1$ & $7 \cdot 0$ & 5.7 & 5.8 \\
\hline 7 & $\mathrm{~F}$ & 64 & $31 \cdot 6$ & 7 & $6 \cdot 5$ & 6.9 & $5 \cdot 9$ & $6 \cdot 1$ \\
\hline Mean & & 62 & 28.9 & 6 & $7 \cdot 5$ & 7.6 & 6.9 & 6.8 \\
\hline $\mathrm{SE}$ & & 1 & 1.8 & 2 & 0.4 & $0 \cdot 3$ & 0.5 & 0.5 \\
\hline
\end{tabular}

Meal A, $50 \mathrm{~g}$ white bread; meal $\mathrm{B}, 30 \mathrm{~g}$ rice; meal C, $100 \mathrm{~g}$ white bread; meal $\mathrm{D}, 60 \mathrm{~g}$ rice.

carbohydrate source. Furthermore, comparison of glycaemic responses is difficult due to varying amounts of starch ingested by the participants; e.g. $22 \mathrm{~g} \mathrm{CHO}$ (Heinonen et al. 1985), $39 \mathrm{~g}$ CHO (Arends et al. 1987), $111 \mathrm{~g} \mathrm{CHO} \mathrm{(Wolever} \mathrm{et} \mathrm{al.} \mathrm{1988).} \mathrm{To} \mathrm{see} \mathrm{if} \mathrm{the}$ amount of $\mathrm{CHO}$ influences the GI, the glycaemic response of parboiled rice and white bread to $25 \mathrm{~g}$ and $50 \mathrm{~g}$ CHO was studied in seven NIDDM subjects.

\section{SUBJECTS AND METHODS}

Subjects

Seven NIDDM subjects (five females and two males), fully informed of the experimental nature of the investigation, were studied. The NIDDM subjects were all treated by diet, six received sulphonylurea and two in addition received metformin (subjects nos 3 and 5). The study had the approval of the local ethical committee. Clinical information relating to the participants is given in Table 1. All diabetics were free of neuropathy, nephropathy and retinopathy (except simplex retinopathy in subject no. 5).

\section{Experimental protocol}

Each subject consumed the four meals in random order within a 4-week period. Studies were performed on an outpatient basis after a $12 \mathrm{~h}$ overnight fast. At 08.00 hours on the day of the experiment a catheter was inserted into an antecubital vein to ensure blood samples. Blood samples were collected at $-30,-15,0,15,30,45,60,90,120,180$ and $240 \mathrm{~min}$. The test meals were served at 08.30 hours and ingested continuously over a $10 \mathrm{~min}$ period. Tap water $(250 \mathrm{ml})$ was taken with the meals. The participants took their usual medication at the start of the meal. The patients were asked to micturate before meal intake and the glucose loss was measured in the urine collected during the test period $(0-240 \mathrm{~min})$.

\section{Meals}

The composition of the test meals is given in Table 2. The parboiled white rice (raw weight 30 and $60 \mathrm{~g}$ ) was cooked for $12 \mathrm{~min}$ before ingestion and, like the corresponding amount of white bread (50 and $100 \mathrm{~g}$ ), taken per se. The approximate content of carbohydrate, protein and fat was calculated according to Helms (1980). 
Table 2. Meal composition: content of nutrients of the ingested rice (raw weight) and white bread

( $250 \mathrm{ml}$ tap water was taken with each meal)

\begin{tabular}{lcccc}
\hline & & & & \\
& Wt & Fat & Protein \\
$(\mathrm{g})$ & $(\mathrm{g})$ & $(\mathrm{g})$ & $\begin{array}{c}\text { Carbohydrate } \\
\text { (available) } \\
(\mathrm{g})\end{array}$ \\
\hline \multirow{2}{*}{ Parboiled white rice } & 30 & $0 \cdot 1$ & $2 \cdot 2$ & 24 \\
& 60 & $0 \cdot 2$ & $4 \cdot 4$ & 48 \\
& 50 & $0 \cdot 8$ & $3 \cdot 9$ & 25 \\
& 100 & $1 \cdot 6$ & $7 \cdot 8$ & 50 \\
\hline
\end{tabular}

Analytical techniques

Plasma and urinary glucose were measured by the glucose oxidase $(E C 1.1 .1 .34)$ method. Haemoglobin $\mathrm{A}_{1} \mathrm{c}\left(\mathrm{HbA}_{1} \mathrm{c}\right)$ values were determined by a commercial kit (Bio-Rad, Richmond, CA, USA ; normal values $3 \cdot 5-5 \cdot 5 \%$ ). Serum insulin levels were determined by specific radioimmunoassay.

\section{Statistical methods}

The post-prandial blood glucose and insulin-response areas above basal were calculated geometrically (Jenkins et al. 1981). Blood glucose values below basal values were excluded. The basal glucose concentration was defined as the mean of values obtained at $15 \mathrm{~min}$ and $0 \mathrm{~min}$ before meal intake. Results are expressed as means with their standard errors. Statistical analysis and multiple comparisons between response areas were made by analysis of variance and Student's $t$ test for paired data. The level of statistical significance was set to 0.05 .

\section{RESULTS \\ NIDDM}

Identical $\mathrm{HbA}_{1} \mathrm{c}$ values (\%) were present before the test meals: $30 \mathrm{~g}$ rice 6.4 (SE 1.5$), 60 \mathrm{~g}$ rice 6.5 (SE 6.7), $50 \mathrm{~g}$ white bread 6.7 (SE 2.3) and $100 \mathrm{~g}$ white bread 6.6 (SE 2.9) respectively. No difference in mean fasting blood glucose values between the four meals were seen (Table 1). During the observation period no glucosuria was detected in any of the patients. The post-prandial blood glucose and insulin responses are shown in Fig. 1. Mean blood glucose and insulin-response areas to the four test meals over $180 \mathrm{~min}$ are depicted in Fig. 2. Postprandial blood glucose response areas after 25 and $50 \mathrm{~g} \mathrm{CHO}$ as parboiled white rice (85 (SE 24) $\mathrm{mm} \times 180 \mathrm{~min}$ and 226 (SE 29) $\mathrm{mm} \times 180 \mathrm{~min}$ ) were significantly lower when compared with the corresponding meals of white bread (181 (SE 55) $\mathrm{mm} \times 180 \mathrm{~min}(P<$ $0.01)$ and 423 (SE 76) $\mathrm{mm} \times 180 \mathrm{~min}(P<0 \cdot 01)$ respectively). Similar GI of parboiled white rice after $25 \mathrm{~g} \mathrm{CHO} \mathrm{(55} \mathrm{(SE} \mathrm{10))} \mathrm{and} 50 \mathrm{~g} \mathrm{CHO} \mathrm{(60} \mathrm{(SE} \mathrm{8))} \mathrm{were} \mathrm{found.} \mathrm{There} \mathrm{was} \mathrm{no}$ difference in insulin-response areas after $25 \mathrm{~g} \mathrm{CHO}$ as parboiled white rice (2075 (SE 730) $\mu \mathrm{U} / \mathrm{ml} \times 180 \mathrm{~min})$ and white bread $(2310(\mathrm{SE} 724) \mu \mathrm{U} / \mathrm{ml} \times 180 \mathrm{~min})$, whereas the insulin-response area to $50 \mathrm{~g}$ CHO as white bread (4440 (SE 714) $\mu \mathrm{U} / \mathrm{ml} \times 180 \mathrm{~min}$ ) was significantly higher than that to parboiled white rice $(2502$ (SE 737) $\mu \mathrm{U} / \mathrm{ml} \times 180 \mathrm{~min}$; $P<0 \cdot 05)$. 


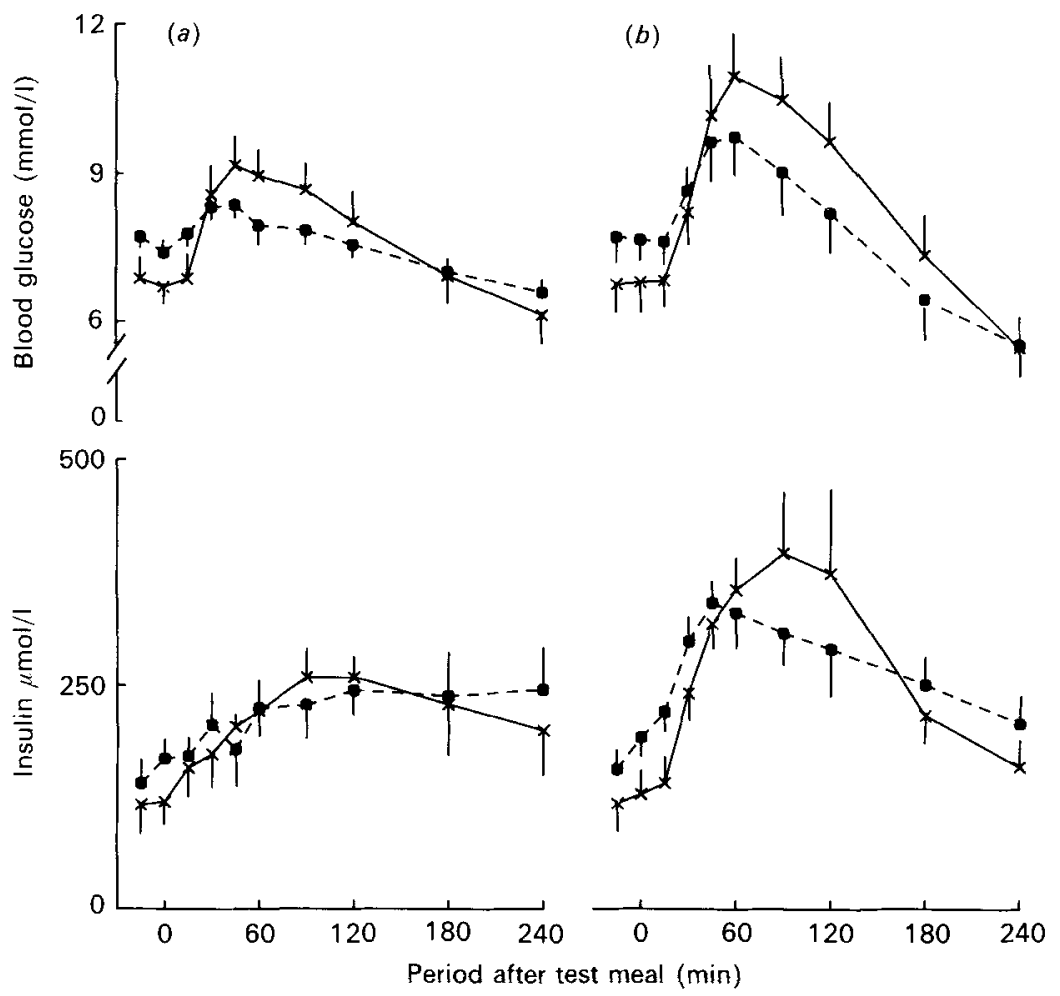

Fig. 1. Mean blood glucose and plasma insulin variations observed after $(a) 30$ and $(b) 60$ g parboiled white rice (raw weight) ( $\square$ ) and the corresponding amount of starch as 50 and $100 \mathrm{~g}$ white bread $(X)$ in seven non-insulindependent diabetic patients. Points are means with their standard errors represented by vertical bars for seven subjects.

\section{DISCUSSION}

Recent studies have demonstrated that starch-rich foods are characterized by distinctive glycaemic responses in normal and NIDDM subjects (Coulston et al. 1980; Crapo et al. 1980, 1981; Bantle et al. 1983; Jenkins et al. 1983, 1984; Hermansen et al. 1986, 1987 ; Hollenbeck et al. 1986; Rasmussen et al. 1989). The glycaemic responses to different starchrich foods are compared with white bread and expressed as GI (Jenkins et al. 1984). Normally amounts of $50 \mathrm{~g}$ carbohydrate are compared. The potential value of these findings in practical diet management of post-prandial hyperglycaemia in diabetic subjects is uncertain, however, as meals of $50 \mathrm{~g}$ CHO of a single food are seldom ingested. The present study was designed to determine if the GI of a food is modified when only half the amount of starch $(25 \mathrm{~g} \mathrm{CHO})$ is ingested in NIDDM patients. We found a similar GI of parboiled white rice to $25 \mathrm{~g} \mathrm{CHO} \mathrm{(55} \mathrm{(SE} \mathrm{10))} \mathrm{and} 50 \mathrm{~g} \mathrm{CHO} \mathrm{(60} \mathrm{(SE} \mathrm{8))} \mathrm{in} \mathrm{seven} \mathrm{NIDDM}$ subjects. The low GI of parboiled white rice found in our study group corroborates previous results (Wolever et al. 1986). Jenkins et al. (1984) found that $25 \mathrm{~g} \mathrm{CHO}$ as white bread constituted blood-glucose-response areas of 48 (SE 4$) \%$ of that of $50 \mathrm{~g} \mathrm{CHO}$ as white bread in a mixed group of tablet- and insulin-treated NIDDM subjects. The proportional increase in post-prandial blood glucose response to white bread is not surprising since the blood glucose response to oral glucose and white bread is similar (Bantle et al. 1983), demonstrating no delay in the post-prandial absorption of glucose from a starch-rich food such as white bread. The proportional blood glucose increase to a low GI food such as parboiled white rice was identical to that of white bread at different levels of starch intake. 

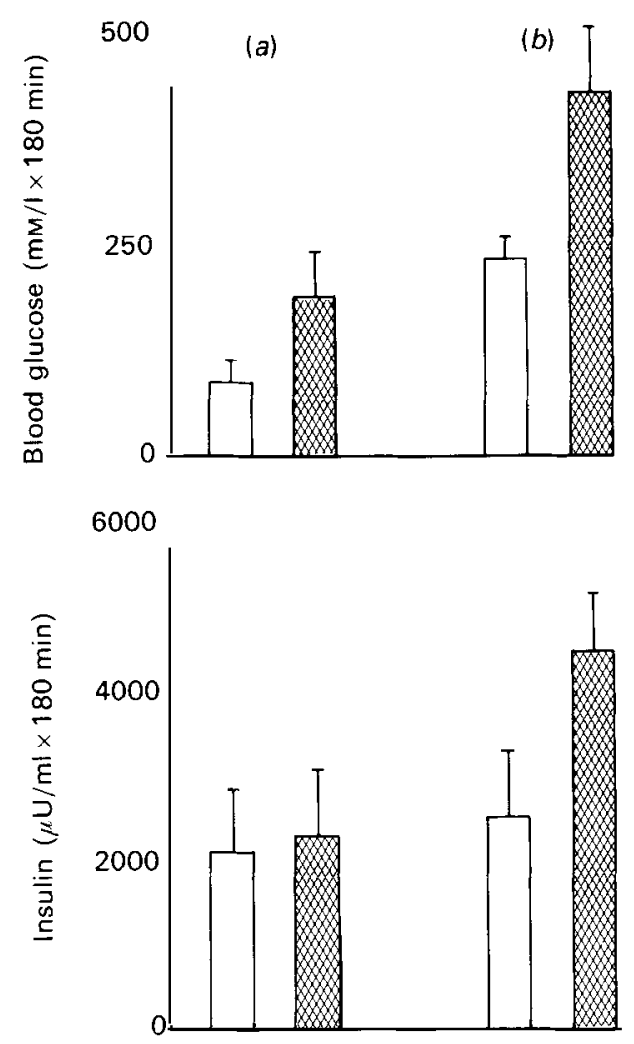

Fig. 2. Mean blood glucose and plasma insulin-response areas in seven non-insulin-dependent diabetic patients to (a) $25 \mathrm{~g}$ and $(b) 50 \mathrm{~g}$ carbohydrate as parboiled white rice ( $\square$ ) and white bread ( $B$ ). Values are means with their standard errors represented by vertical bars for seven subjects.

This implies that the factor responsible for the low glycaemic response of rice, e.g. delayed gastric emptying, decreased access of digestive enzymes to the starch or unabsorbed starch, is not affected by the level of starch intake.

The finding that the insulin-response areas to $25 \mathrm{~g} \mathrm{CHO}$ as parboiled white rice and white bread were similar at different blood glucose rises could appear puzzling, as a major determinant of insulin secretion is the rate of change in the splanchnic blood glucose level. However, we have also found similar blood-glucose-response areas to meals of spaghetti (Rasmussen et al. 1990) taken per se and as part of mixed meals, although the insulin response areas differed significantly. These results underline the low insulin sensitivity in NIDDM subjects, emphasizing that a major determinant of the post-prandial blood glucose rise in NIDDM subjects is the nature of the CHO eaten. Coulston et al. (1987) and Laine et al. (1987) have questioned these findings as these authors found similar plasma glucose and insulin responses to mixed meals derived from $\mathrm{CHO}$ of low, intermediate or high GI in NIDDM subjects. The discrepancy in results might be explained by the relatively high content of monosaccharides $(400 \mathrm{~g} / \mathrm{kg})$ in the mixed meals taken in the latter two studies. In addition, all diabetic patients (Coulston et al. 1987; Laine et al. 1987) had high fasting blood glucose levels $(>9 \mathrm{~mm}$ ) which may dilute differences among glycaemic responses after starch-rich foods due to the enhanced glucose clearance by muscle and kidneys. Thus, in IDDM subjects we have previously found significantly subdued glycaemic responses at a pre-prandial blood glucose of $9 \mathrm{~mm}$ compared with a level of $6 \mathrm{~mm}$ 
(Rasmussen \& Hermansen, 1991). In our groups the fasting blood glucose levels were close to normal, and we found no difference in the amount of glucose loss in the urine during the study period.

In conclusion, our results indicate that the GI of starch-rich food is not affected by the amount of starch ingested in NIDDM patients.

The authors thank Eva Seier for expert technical assistance. This work was supported by grants from the Danish Diabetes Association and the Nordic Insulin Foundation.

\section{REFERENCES}

Arends, J., Arends, K., Lubke, D. \& Willms, B. (1987). Physical factors influencing the blood glucose response to different breads in type II diabetic patients. Die Nahrung $65,469.474$.

Bantle, J. P., Laine, D. C., Castle, G. W., Thomas, J. W., Hoogwerf B. J. \& Goetz F. C. (1983). Postprandial glucose and insulin responses to meals containing different carbohydrates in normals and diabetic patients. New England Journal of Medicine 309, 7-12.

Coulston, A., Greenfield, M. S., Kraemer, F. B., Tobey, T. A. \& Reaven, G. M. (1980). Effect of source of dietary carbohydrate on plasma glucose and insulin responses to test meals in normal subjects. American Journal of Clinical Nutrition 33, 1279-1282.

Coulston, A., Hollenbeck, C. B., Swislocki, A. L. M. \& Reaven, G. M. (1987). Effect of source of dietary carbohydrate on plasma glucose and insulin responses to mixed meals in subjects with NIDDM. Diabetes Care 10, $395-400$.

Crapo, P. A., Insel, J., Sperling, M. \& Kolterman, O. G. (1981). Comparison of serum glucose, insulin and glucagon responses to different types of complex carbohydrates in non-insulin-dependent diabetic patients. American Journal of Clinical Nutrition 34, 184-190.

Crapo, P. A., Kolterman, O. G., Waldec, N., Reaven, G. M. \& Olefsky, J. M. (1980). Postprandial hormonal responses to different types of complex carbohydrate in individuals with impaired glucose tolerance. American Journal of Clinical Nutrition 33, 1723-1728.

Fontvieille, A. M., Acosta, M., Rizkalla, S. W., Bornet, F., David, P., Letanoux, M., Tchobroutsky, G. \& Slama, G. (1988). A moderate switch from high to low glycaemic-index foods for 3 weeks improves the metabolic control of type 1 (IDDM) diabetic subjects. Diabetic Nutrition and Metabolism I, 139-143.

Heinonen, L., Korpela, R. \& Mantere, S. (1985). The effect of different types of Finnish bread on postprandial glucose response in diabetic patients. Human Applied Nutrition 39A, $108 \cdots 113$.

Helms, P. (1980). Kost vurderingstabeller (Food Tables). Copenhagen: Akademisk Forlag.

Hermansen, K., Rasmussen, O., Arnfred, J., Winther, E. \& Schmitz, O. (1986). Differential glycaemic effects of potato, rice and spaghetti in type 1 (insulin-dependent) diabetic subjects. Diabetologia 29, 358-361.

Hermansen, K., Rasmussen, O., Arnfred, J., Winther, E. \& Schmitz, O. (1987). Glycemic effects of spaghetti and potato consumed as part of a mixed meal in IDDM patients. Diabetes Care 10, $401-406$.

Hollenbeck, C. B., Coulston, A. M. \& Reaven, G. M. (1986). Glycemic effects of carbohydrate: a different perspective. Diabetes Care 9, 641-647.

Jenkins, D. J. A., Wolever, T. M. S., Buckley, G., Lam, K. Y., Giucidi, S., Kalmusky, J., Jenkins, A. L., Patten, R. L., Bird, J., Wong, G. S. \& Josse, R. G. (1988). Low glycemic-index foods in the diabetic diet. American Journal of Clinical Nutrition 48, 248-254.

Jenkins, D. J. A., Wolever, T. M. S., Jenkins, A. L., Josse, R. G. \& Wong, G. S. (1984). The glycemic response to carbohydrate foods. Lancet ii, 388-391.

Jenkins, D. J. A., Wolever, T. M. S., Jenkins, A. L., Thorne, M. J., Kalmusky, J., Reichert, R. \& Wong, G. S. (1983). The glycaemic index of foods tested in diabetic patients: A new basis for carbohydrate exchange favouring the use of legumes. Diabetologia 24, 257-264.

Jenkins, D. J. A., Wolever, T. M. S., Taylor, R. H., Barker, H., Hashmein, F., Baldwin, J. M., Bowling, A. C., Newman, H. C., Jenkins, A. L. \& Goff, D. V. (1981). Glycemic index of foods, a physiological basis for carbohydrate exchange. American Journal of Clinical Nutrition 34, 362-366.

Jenkins, D. J. A., Wolever, T. M. S., Wong, G. S., Kenshole, A., Josse, R, G., Thompson, L. U. \& Lam, K. Y. (1984). Glycemic responses to foods: possible differences between insulin-dependent and non-insulin-dependent diabetics. American Journal of Clinical Nutrition 40, 971-981.

Laine, D. C., Thomas, W., Levitt, M. D. \& Bantle, J. P. (1987). Comparison of predictive capabilities of diabetic exchange lists and glycemic index of foods. Diabetes Care 10, 387-394.

Rasmussen, O., Gregersen, S. \& Hermansen, K. (1990). The predictive capability of the glycaemic response to spaghetti in non-insulin dependent diabetic (NIDDM) and insulin dependent (IDDM) diabetic subjects. Journal of Internal Medicine 228, 97-103.

Rasmussen, O. \& Hermansen, K. (1991). Influence of preprandial blood glucose values on glycemic responses in insulin-dependent diabetes mellitus (IDDM) at constant insulinemia. American Journal of Clinical Nutrition 53, $520-523$. 
Rasmussen, O., Winther, E. \& Hermansen, K. (I989). Postprandial glucose and insulin responses to rolled oats ingested raw, cooked or as a mixture with raisin in normal and type 2 diabetic patients. Diabetic Medicine 6 , 337-341.

Wolever, T. M. S. Csima, A., Jenkins, D. J. A., Wong, G. S. \& Josse, R. G. (1989). The glycemic index: Variation between subjects and predictive differences. Journal of American College of Nutrition 8, 235-247.

Wolever, T. M. S., Jenkins, D. J. A., Kalmusky, J., Jenkins, A., Giordano, C., Giudici, S., Josse, R. G. \& Wong, G. S. (1986). Comparison of regular and parboiled rices: explanation of discrepancies between reported glycemic responses to rice. Nutrition Research 6, 349-357.

Wolever, T. M. S., Jenkins, D. J. A., Ocana, A. M., Rao, V. A. \& Collier, R. (1988). Second-meal effect: Lowglycemic-index foods eaten at dinner improve subsequent breakfast glycemic response. American Journal of Clinical Nutrition 48, $1041-1047$.

Wolever, T. M. S., Jenkins, D. J. A., Vuksan, V., Josse, R. G., Wong, G. S. \& Jenkins, A. L. (1990). Glycemic index of foods in individual subjects. Diabetes Care 13, 126-132. 